\title{
Reflexiones en torno al régimen de subsidios y contribuciones en los sectores de acueducto, alcantarillado y aseo
}

\section{Reflections on the subsidies and contributions system in the areas of water supply, sewerage and cleaning}

Fecha de recepción: 3 de mayo de 2011 Fecha de evaluación: 16 de junio de 2011 Fecha de aprobación: 21 de junio de 2011

\author{
Ómar Alfonso Ochoa Maldonado*
}

\section{RESUMEN}

El régimen jurídico aplicable al tema del otorgamiento de subsidios y contribuciones a sectores con menor capacidad adquisitiva de la población ha sido objeto de múltiples interpretaciones y cambios en su marco normativo, a raíz de una serie de desarrollos reglamentarios proferidos por el Gobierno Nacional y de algunos fallos jurisdiccionales que han dejado sin piso algunas iniciativas gubernamentales en la materia. Así las cosas, el presente trabajo pretende determinar cuáles son los principales problemas que surgen en esa materia, especialmente a nivel de las entidades territoriales, a raíz de las múltiples transformaciones que recientemente sufrió el marco regulatorio aplicable a esta temática.

Palabras clave: Subsidios, contribuciones, servicios públicos domiciliarios, tarifas, acueducto, alcantariIlado, aseo, saneamiento básico

* Abogado con grado de honor de la Universidad Nacional de Colombia. Especialista en Gestión Pública e Instituciones Administrativas, Universidad de los Andes; en Derecho Constitucional y en Derecho Privado Económico; Universidad Nacional de Colombia, candidato a magíster en Derecho Económico, Pontificia Universidad Javeriana. Actual jefe de la Oficina de Control Interno de la Superintendencia de Servicios Públicos Domiciliarios. 


\section{ABSTRACT}

The legal system applicable to the topic of the grant of subsidies and contributions to sectors of the population with smaller acquisitive capacity, has been the object of multiple interpretations and changes in its normative frame, because of a series of regulation developments uttered by the National Government and of some jurisdictional failures that have left without grounds some governmental initiatives in the matter. Taking these aspects into consideration, the present article tries to determine which are the main problems that arise in this matter, especially at a local authorities level, due to the various recent transformations the regulations applicable to this thematic have suffered.

Keywords: Subsidies, contributions, public domiciliary services, rates, aqueduct, sewerage, cleaning, basic sanitation.

\section{INTRODUCCIÓN}

En el marco del Estado social de derecho como categoría jurídico-política prohijada por el ideario constitucional, la prestación de los servicios públicos domiciliarios reviste una especial relevancia, en procura de materializar no solamente la función social que le es inherente al modelo de Estado adoptado, sino como un instrumento necesario para la concreción de las finalidades que inspiran el accionar del andamiaje estatal en su conjunto.

En ese orden de ideas, los artículos 367 y 368 de la Constitución Política constituyen el asidero de estirpe superior que moldea el perfil y características del régimen de contribuciones y subsidios en materia de servicios públicos domiciliarios, señalándose expresamente que para el efecto se deben tener en cuenta, entre otros, los principios de solidaridad y redistribución de ingresos. En efecto, el primer artículo reseñado en precedencia dispone expresamente que el régimen tarifario debe tener en cuenta, además del criterio de costos, los de solidaridad y redistribución de ingresos.

Por su parte, el artículo 368 superior autoriza expresamente a la nación, a los departamentos, a los distritos, a los municipios y a las entidades descentralizadas para conceder subsidios con cargo a sus presupuestos, en aras de favorecer al sector poblacional con menor nivel de ingresos, en lo referente a la cobertura de sus necesidades básicas vinculadas a la prestación de servicios públicos domiciliarios.

En desarrollo de los anteriores preceptos, la Ley 142 de 1994 consagra el marco de talante legal que regula el régimen de contribuciones y subsidios, concebidos estos como instrumentos de intervención estatal que propugnan por dotar de contenido las finalidades de solidaridad y redistribución de ingresos que sirven como norte orientador del esquema tarifario, y que de contera tienen como objetivo palmario materializar el valor de justicia social y promover condiciones para que la igualdad sea real y efectiva, tal como lo pregona con ahínco el artículo 13 superior.

Para el efecto, la citada norma consigna en su contenido la creación de aportes denominados contribuciones de solidaridad y lo propio hace con la categoría de los subsidios; conceptos ambos que parten del supuesto del diferencial en el cobro del valor de los servicios públicos por estratos socioeconómicos, en consonancia con la capacidad económica de cada segmento de usuarios, para encauzar esfuerzos económicos hacia el costo de cubrimiento de los servicios públicos domiciliarios, respecto a sectores con bajo nivel de ingreso, los 
cuales, en condiciones de mercado, no tendrían acceso a la infraestructura de este tipo de servicios, necesarios para la concreción del mínimo vital'.

Dicha estructura es consecuente con la finalidad constitucionalmente establecida, en el sentido de señalar como derroteros de forzosa observancia la solidaridad y la redistribución de ingresos; telos que tiene como objetivo que los usuarios pertenecientes a sectores de estratos altos y productivos (industriales y comerciales) coadyuven en el financiamiento de los costos necesarios para proveer del acceso a los servicios públicos domiciliarios a las personas pertenecientes a sectores deficitarios. Cabe resaltar que se encuentran exentos del pago de esta contribución hospitales, clínicas, puestos y centros de salud, y centros educativos y asistenciales sin ánimo de lucro, discriminación positiva justificada por el especial objeto de contenido social al cual enfocan su accionar (numeral 7, artículo 89, Ley 142 de 1994).

1 Frente a esa categoría, es pertinente señalar que la Corte Constitucional ha decantado una línea jurisprudencial en materia de las características del derecho al agua como fundamental y susceptible de amparo vía acción de tutela, para efectos ilustrativos en Sentencia T-381 de 2009, m.p. doctor Jorge Ignacio Pretelt, dicha Corporación señaló:

“Derecho fundamental al agua apta para el consumo humano. Reiteración de jurisprudencia.

“8. Desde sus primeras sentencias, esta Corporación ha mantenido una tesis uniforme en cuanto a la protección de los derechos fundamentales que se derivan del suministro de agua apta para el consumo humano y de un servicio de alcantarillado que lo permita, pues ha concluido que el agua potable constituye un derecho fundamental que hace parte del núcleo esencial del derecho a la vida en condiciones dignas cuando está destinada al consumo humano. En esa línea, entonces, la Corte ha dicho que el derecho al agua puede protegerse por medio de la acción de tutela cuando contribuye a la vida, la salud y salubridad de las personas, pero no lo es cuando está destinada a otras actividades, tales como la explotación agropecuaria o a terrenos deshabitados.

en efecto, son numerosas las sentencias proferidas por las distintas salas de revisión de esta Corporación que definen los casos en los que procede la tutela para exigir de las autoridades públicas y de los particulares la adecuada, eficiente y oportuna prestación del servicio público de acueducto y alcantarillado, si se tiene en cuenta la especial importancia que para el Estado social de derecho tiene la solución de las necesidades insatisfechas de la población en particular respecto del "saneamiento ambiental y de agua potable" (artículos 365 y 366 de la Constitución).
En ese orden de ideas, el artículo 89.1 de la citada Ley 142 de 1994, en materia de la aplicación de los mencionados criterios de solidaridad y redistribución de ingresos, establece que el "factor"2 que se debe aplicar para el otorgamiento de subsidios, de los cuales son beneficiarios los usuarios pertenecientes a los estratos 1, 2 y 3, no podrá ser superior al equivalente al veinte por ciento (20\%) del valor del servicio y, adicionalmente, se indica en la normativa sub examine que no podrán incluirse factores adicionales por concepto de ventas o consumo del usuario, para el cómputo del citado porcentaje máximo. Como complemento a lo anterior, la norma en cita dispone que las comisiones de regulación solamente permitirán que el factor que se cobra se incorpore en las facturas de los usuarios correspondientes a los inmuebles residenciales de los estratos 5 y 6 , y en las de los usuarios catalogados como industriales y comerciales, tal como se reseñó en precedencia.

Como corolario que deriva del anterior acervo, el numeral 89.2 del artículo 89 de la mencionada ley señala que los prestadores de servicios públicos deben efectuar los recaudos de los valores resultantes de la aplicación de los factores de sobreprecio, los cuales se destinarán forzosamente al pago de subsidios a favor de los beneficiarios ya mencionados.

Cabe resaltar en este acápite que el artículo 2 de la Ley 632 de 2000 modifica el citado artículo 89 de la Ley 142 de 1994, en el sentido de establecer que el monto máximo de las contribuciones para los servicios de acueducto, alcantarillado y aseo será "lo necesario para asegurar que el monto de las contribuciones sea suficiente para cubrir los subsidios que se apliquen".

2 El mencionado "factor" ostenta diferentes denominaciones en el ordenamiento positivo. La Ley 142 de 1994 lo denomina "factor", a su vez la Ley 143 de 1994 lo signa como "contribución", y por último la Ley 223 de 1995 hace referencia a la categoría "sobretasa o contribución especial". 
La anterior disposición es la respuesta legislativa a una tozuda realidad; el límite del veinte por ciento $(20 \%)$ no es suficiente para alcanzar puntos de equilibrio entre contribuciones especiales y subsidios, razón que justifica establecer límites superiores de acuerdo con las necesidades específicas de cada ente territorial, para garantizar la sostenibilidad financiera del esquema. Lo anterior, por cuanto el sustrato económico es en últimas el elemento determinante que permite el nivel de efectividad de los derechos, frente a lo cual algún sector de la doctrina se ha inclinado en materia constitucional a referenciar la categoría de países en vías de desarrollo de "constitucionalismo del tercer mundo" (Díaz Arenas, 1994), refiriéndose a aquellos que reconocen prolíficamente una serie de prerrogativas con rango incluso constitucional, pero que no cuentan con un nivel de suficiencia económica que permita que esos derechos sean reales y efectivos, convirtiéndose en simples postulados retóricos desprovistos de toda eficacia práctica.

Es pertinente precisar que los subsidios no pueden exceder el valor de los consumos básicos o de subsistencia, razón por la cual cuando estos se conceden no cubren los valores asociados a costos de administración, operación y mantenimiento (artículo 99 de la Ley 142 de 1994).

Sobre esta materia en particular, el otorgamiento directo de los subsidios a los sectores vulnerables se realiza por conducto de las entidades territoriales a través de los fondos de solidaridad y garantía o de su propio presupuesto. Estos mecanismos se han visto en la praxis impactados en cuanto a su funcionalidad, a raíz de los recientes cambios normativos y de los pronunciamientos judiciales proferidos sobre las normas que soportan este esquema, los cuales serán objeto de ulterior estudio en el acápite pertinente.

\section{ESTRUCTURA FINANCIERA PARA EL OTORGAMIENTO DE SUBSIDIOS}

En relación con las fuentes de financiamiento de los mencionados subsidios se ha señalado:

Los criterios de solidaridad y redistribución de ingresos se materializan a través de: 1. El cobro de los aportes solidarios o contribuciones a quienes tienen mayor capacidad económica. 2. El cruce interno de los subsidios y contribuciones o aportes solidarios por parte de las empresas. 3. La destinación de recursos por parte de la nación, entidades territoriales y descentralizadas para la aplicación de los subsidios, y 4. La asignación de recursos a través de los fondos de solidaridad y redistribución de ingresos (Castro, 2010: 61).

Respecto a los mencionados fondos de solidaridad y redistribución de ingresos, la ley bajo estudio creó este tipo de instrumento financiero sobre el cual la doctrina ha señalado lo siguiente:

\footnotetext{
El objetivo de los fondos de solidaridad y redistribución de ingresos es canalizar los recursos destinados a sufragar subsidios para que las personas de menores ingresos puedan pagar los servicios públicos domiciliarios.

El fondo de solidaridad y redistribución de ingresos es, como ha quedado explícito desde un principio, una cuenta dentro del respectivo presupuesto de la entidad a la que pertenece.

A través de ella se contabilizarán todos los recursos que, en virtud de la decisión de la administración territorial correspondiente, se destinen para otorgar subsidios para el pago de los servicios públicos domiciliarios (Bedoya, 1997: 95).
}

Por mandato contenido en la multicitada Ley 142 de 1994, es atribución de los concejos municipales la creación de los mencionados fondos de solidaridad y redistribución de ingresos, cuya finalidad básica es la incorporación al presupuesto de la entidad territorial de las transferencias que efectúan 
Ios prestadores de servicios públicos, cuya destinación específica es la concesión de subsidios.

La naturaleza jurídica de los mencionados fondos la encontramos contenida en el Decreto 565 de 1996, el cual señala que se trata de cuentas especiales dentro de la contabilidad de los municipios, distritos y departamentos, a través de las cuales se contabilizarán exclusivamente los recursos destinados a otorgar subsidios, para el acceso a los servicios públicos domiciliarios. Cabe resaltar, en consecuencia, que se trata de cuentas sin personería jurídica, dotadas de una contabilidad separada e independiente, para asegurar la finalidad específica a la cual se encuentran afectos, de tal suerte que no pueden hacer unidad de caja con los demás recursos de la entidad territorial.

En torno a la calidad de los recursos pertenecientes a los mencionados fondos, y su necesaria incorporación a los mismos, como requisito para efectuar erogaciones con cargo a estos, se ha señalado por parte de la jurisprudencia lo siguiente:

\begin{abstract}
Tanto el factor que se aplica a los usuarios de los estratos altos -cuya naturaleza tributaria se deduce de ser una erogación obligatoria destinada a una finalidad pública y sin contraprestacióncomo los "aportes directos", se contabilizan, registran e incorporan en los respectivos presupuestos de la nación, los departamentos, los distritos y los municipios, pues, al destinarse ambos recursos a la financiación de los subsidios para pagar las tarifas de los usuarios de menores recursos, configuran gasto público que no puede hacerse si no se incluye en aquellos (C.P., art. 345) (Consejo de Estado, Sala de lo Contencioso Administrativo, Sección Tercera, consejero ponente doctor Ramiro Saavedra Becerra, Bogotá, D.C., treinta y uno (31) de julio de dos mil tres (2003). Radicación No. ACU- 25000-23-24-000-200202855-01).
\end{abstract}

De lo anterior se infiere que la utilización de los recursos que hacen parte de los mencionados fondos constituye gasto público social, el cual por mandato constitucional (art. 366, C.P.) tiene prelación sobre cualquier otra erogación en la conformación de los respectivos presupuestos de la nación y de las entidades territoriales.

\section{NATURALEZA JURÍDICA DE LAS CONTRIBUCIONES SOLIDARIAS}

Hemos indicado hasta ahora que las contribuciones son recursos que se arbitran con cargo a los usuarios pertenecientes a estratos socioeconómicos altos, así como a los de naturaleza industrial y comercial, y que son el resultado de aplicar al valor del servicio el factor de que trata la Ley 142 de 1994, modificado por el artículo 2 de la Ley 632 de 2000, diferenciándose de aquel en la respectiva factura, cuya finalidad es coadyuvar en la conformación del esquema financiero, necesario para subsidiar los costos básicos de los servicios a los usuarios beneficiarios de los mismos.

Así las cosas, es pertinente en este acápite auscultar la naturaleza jurídica de la mencionada contribución, aspecto de la mayor envergadura para abordar la temática final de este trabajo, en torno a las problemáticas que afronta la materia debatida a lo largo del presente artículo.

La Corte Constitucional, en Sentencia C-086 de 1998, señaló con claridad que las contribuciones correspondientes al sector eléctrico y gas combustible revisten el carácter de un impuesto del orden nacional con destinación específica, toda vez que ostentan el carácter de general frente a los destinatarios de las mismas, tienen estirpe vinculante $y$, a diferencia de las tasas, su pago no retribuye en contraprestación o recepción de un servicio administrativo.

Desde esa óptica, señala la jurisprudencia constitucional en la referida sentencia las siguientes razones para concluir que se trata de una exacción de naturaleza tributaria. Se afirma que este 
sobrecosto en los servicios públicos domiciliarios es un impuesto por los siguientes motivos:

Su imposición no es el resultado de un acuerdo entre los administrados y el Estado. El legislador, en uso de su facultad impositiva (artículo 150, numeral 12), y en aplicación del principio de solidaridad que exige la Constitución en materia de servicios públicos, como de los principios de justicia y equidad (artículo 95, numeral 9 y 338 de la Constitución), decidió gravar a un sector de la población que, por sus características socioeconómicas, podría soportar esta carga.

Su pago es obligatorio, y quien lo realiza no recibe retribución alguna; razón por la que no se puede afirmar que este pago es una tasa o sobretasa, pues este no es retribución del servicio prestado, no existe beneficio alguno para quien lo sufraga, y el usuario no tiene la opción de no pago.

Los elementos de este gravamen se pueden identificar así:

- Los usuarios de los sectores industriales y comerciales, y los de los estratos 5 y 6 , se constituyen en los sujetos pasivos.

- Las empresas que prestan el servicio público son los agentes recaudadores.

- El hecho gravable lo determina el ser usuario de los servicios públicos que prestan las empresas correspondientes.

- La base gravable la constituye el valor del consumo que está obligado a sufragar el usuario.

- El monto del impuesto, si bien no está determinado directamente por la ley, sí es determinable, pues se establece que no podrá ser mayor al $20 \%$ del valor del servicio prestado. Para el efecto, se delega en las comisiones de regulación correspondientes la fijación dentro de este límite del porcentaje que se debe cobrar.

- Tratándose del servicio público de energía, el monto de este se fijó directamente en un
20\% del valor del servicio (Ley 223 de 1995, artículo 95). (Corte Constitucional. Sala plena. Sentencia C-086 de 1998. Magistrado ponente doctor Jorge Arango Mejía, marzo 18 de 1998. Expediente D-1771).

Nótese cómo de la conclusión a que arriba se refiere la Corte frente a la naturaleza de las contribuciones se desprenden varios elementos de gran valía para el análisis en ciernes. Al tratarse de un tributo, sus elementos configurantes a que alude el artículo 338 de la Carta tienen reserva de ley y en consecuencia no le es dable al ejecutivo fijar el factor de la citada contribución por vía reglamentaria. Por otro lado, respecto a las contribuciones relativas al sector eléctrico y las aplicables al gas combustible, ostentan la calidad de un impuesto nacional con destinación específica, circunstancia que si bien está proscrita por el artículo 359 de la Constitución en forma general, claramente se encuentra excepcionada en el numeral segundo del citado artículo, el cual señala que dicha restricción no aplica tratándose de inversión social y el otorgamiento de los subsidios de conformidad con lo señalado en el punto anterior se considera como gasto público social por antonomasia.

Frente a ese particular, es pertinente indagar acerca de la naturaleza jurídica de las contribuciones por solidaridad relativas al sector de agua potable y saneamiento básico, respecto de las cuales es acertado señalar que se tratan de un tributo, por cuanto reúnen los requisitos a que se refiere la Corte Constitucional en la citada Sentencia C-086 de 1998. Sin embargo, no pueden catalogarse en modo alguno como tributos del orden nacional, tal como ocurre con las contribuciones relativas al sector eléctrico y gas natural, por las razones que pasan a esbozarse a continuación:

En primer lugar, este tipo de contribuciones por solidaridad no ingresan a las arcas nacionales; como se ha indicado precedentemente, su destino es la conformación de los fondos de solidaridad y 
redistribución de ingresos en el ámbito territorial, los cuales a su vez son cuentas especiales dentro de la contabilidad de los municipios, a través de las cuales se contabilizan exclusivamente los recursos destinados a otorgar subsidios a los servicios públicos domiciliarios (artículo 4 del Decreto 565 de 1996).

Por otro lado, contrario a lo que ocurre con las contribuciones propias del sector eléctrico y de gas natural cuyos elementos configurantes se encuentran establecidos en normas de talante legal (Ley 286 de 1996), no ocurre lo mismo tratándose de las contribuciones del sector acueducto, alcantarillado y aseo, respecto de las cuales, según el esquema vigente, las entidades territoriales, a través de sus corporaciones de representación popular, son las Ilamadas a establecer el porcentaje necesario para asegurar que el monto de las contribuciones sea suficiente para cubrir los subsidios que se apliquen al tenor de lo dispuesto en el artículo 2 de la Ley 632 de 2000.

En ese orden de ideas, no solamente las entidades territoriales son receptoras de los recursos que se arbitran por ese concepto, sino que participan decisivamente en establecer uno se los elementos esenciales del mismo, cual es el porcentaje respectivo, lo cual denota que las contribuciones del sector de agua potable y saneamiento básico, si bien son impuestos, no lo son del orden nacional sino territorial.

Sobre ese particular, en la misma sentencia la Corte Constitucional señaló:

Por otra parte, para determinar si este tributo es de carácter nacional o territorial, es necesario recurrir a la definición que la jurisprudencia constitucional ha establecido en esta materia. Según esta, una de las formas de determinar si un gravamen es de carácter nacional o territorial, consiste en hacer uso del criterio orgánico según el cual, 'basta identificar si, para el perfeccionamiento del respectivo régimen tributario, es suficiente la intervención del legislador o, si adicionalmente, es necesaria la participación de alguna de las corporaciones locales, departamentales o distritales de elección popular habilitadas constitucionalmente para adoptar decisiones en materia tributaria (C.P., 338). En la medida en que una entidad territorial participa en la definición del tributo, a través de una decisión política que incorpora un factor necesario para perfeccionar el respectivo régimen y que, en consecuencia, habilita a la administración para proceder al cobro, no puede dejarse de sostener que la fuente tributaria creada le pertenece $y$, por lo tanto, que los recursos captados son recursos propios de la respectiva entidad' (Sentencia C-219 de 1997. Magistrado ponente doctor Eduardo Cifuentes Muñoz) (Corte Constitucional, Sala Plena, ibídem).

En el mismo sentido, la Comisión de Regulación de Agua Potable y Saneamiento Básico ha conceptuado acerca de la naturaleza de las contribuciones en comento al señalar:

El artículo en mención -2 de la Ley 632 de 2000- consagra un término de transición respecto a los subsidios y contribuciones de solidaridad en los servicios de acueducto, alcantarillado y aseo. Al hacerlo, abre el camino para que el porcentaje de contribución de solidaridad a ser pagado (lo cual constituye la tarifa del tributo) sea determinado por la entidad territorial, en el marco definido por la regulación y la ley, según la proporción del desmonte de subsidios que estas señalen.

Así, en virtud de tal especificidad legal, propia de los servicios de agua potable y saneamiento básico, las entidades territoriales tienen ciertas facultades determinantes del tributo, lo cual permite concluir, en aplicación del criterio orgánico definido por la Corte, el carácter territorial del tributo (Comisión de Regulación de Agua Potable y Saneamiento Básico, CRA. Concepto CRA-OJ 4216 de 2004. Noviembre 30).

Así las cosas, forzoso es concluir que nos encontramos en presencia de un tributo de carácter 
territorial, tratándose de las contribuciones por solidaridad correspondientes a los sectores de acueducto, alcantarillado y aseo, y en tal sentido su naturaleza fiscal hace imperativo por mandato constitucional que sus elementos sean definidos por el organismo de representación popular; elemento de la mayor envergadura para la cabal comprensión de la problemática generada en torno a los porcentajes de aplicación a que se hará referencia en los siguientes apartados.

\section{FORMAS DE OTORGAMIENTO DE LOS SUBSIDIOS}

El régimen de servicios públicos domiciliarios establece dos formas de otorgar los subsidios:

1. A través del cobro de las contribuciones de solidaridad, las cuales en el caso del sector de acueducto, alcantarillado y aseo revisten el carácter de un tributo del orden territorial según el razonamiento constitucional referenciado en el anterior punto. Dicha obligación tributaria es exigible de los usuarios pertenecientes a los estratos 5 y 6 y al sector industrial y comercial. A su vez, dicho monto, según la Ley 142 , no podrá ser superior al veinte por ciento $(20 \%)$ del valor del servicio. No obstante lo anterior, como se ha indicado previamente, la Ley 632 de 2000 consagra la posibilidad de modificar ese límite cuantitativo en la cuantía necesaria para cubrir los subsidios otorgados.

2. Incorporando las respectivas apropiaciones presupuestales en la conformación de los presupuestos de la nación o de las entidades territoriales, con la finalidad de efectuar gasto público social en materia del otorgamiento de este tipo de subsidios.

Huelga resaltar que en este caso la obligación de aportar recursos de su presupuesto por parte de la nación o de las entidades territoriales solamente es exigible en caso de que los recursos de los fondos de solidaridad y redistribución de ingresos, a que nos hemos referido en el punto $1^{\circ}$ del presente artículo, no sean suficientes para el cumplimiento de su cometido (art. 368, C.P.).

\section{DESARROLLO REGLAMENTARIO Y ANÁLISIS JURISPRUDENCIAL}

En ejercicio de la facultad reglamentaria a que alude el numeral 11 del artículo 189 de la Carta, en relación con la Ley 632 de 2000, el Gobierno Nacional expidió el Decreto 057 de 2006, en cuyos artículos 3 y 7 estableció lo siguiente:

Artículo $3^{\circ}$. Nivel mínimo del factor de aporte solidario. Para cada uno de los servicios de acueducto, alcantarillado y aseo, el nivel mínimo del factor de aporte solidario a que hace referencia el artículo 89.1 de la Ley 142 de 1994, será el que se define a continuación:

Usuarios residenciales de estrato 5: $(50 \%)$

Usuarios residenciales de estrato 6: $(60 \%)$

Usuarios comerciales: (50\%)

Usuarios industriales: (30\%)

Parágrafo. Ante la ausencia de criterios de asignación por parte del alcalde respectivo, según lo dispuesto en el artículo $6^{\circ}$ del Decreto 565 de 1996, la persona prestadora repartirá entre los usuarios por ella atendidos los subsidios provenientes de los recursos derivados de la aplicación del factor de aporte solidario, aplicando en el interior de cada municipio el mismo porcentaje a usuarios pertenecientes al mismo estrato. En todo caso, deberá mantenerse una proporción mínima de 1,25 veces el porcentaje aplicado al estrato 1 en relación con el estrato 2,y de 2,67 veces el porcentaje aplicado al estrato 2 en relación con el estrato 3, sin superar en ningún caso los topes máximos de subsidios señalados por la ley.

El otorgamiento de subsidios al estrato 3 deberá sujetarse a las condiciones y requisitos que para el efecto establezca la Comisión de Regulación de 
Agua Potable y Saneamiento Básico, de acuerdo con lo señalado en el artículo 99.7 de la Ley 142 de 1994.

\begin{abstract}
Artículo $7^{\circ}$. Modificado por el art. 2, Decreto Nacional 2825 de 2006. Si, una vez aplicados los procedimientos mencionados en el artículo anterior no se lograre el equilibrio entre subsidios y contribuciones, durante los seis meses siguientes a la entrada en vigencia del presente decreto, las personas públicas prestadoras de los servicios públicos domiciliarios de acueducto, alcantarillado y aseo asumirán dentro de su ámbito de operación los montos que permitan lograr dicho equilibrio, tomando como referente el porcentaje de los subsidios aplicados a diciembre de 2005 en los correspondientes municipios y/o distritos.
\end{abstract}

Por conducto de la normativa transcrita, el Gobierno Nacional pretendió hacer uso de la facultad que expresamente le difería el artículo 2 de la Ley 632 de 2000, en lo referente al establecimiento de una metodología para la determinación del equilibrio entre las contribuciones que se recaudan frente a la cobertura de los subsidios que se aplican.

En torno a esa temática, de vieja data se había expedido el Decreto 1013 de 2005, en el cual se establece la metodología para el cálculo del ajuste de la contribución, en aras de lograr el equilibrio entre contribuciones y subsidios a que alude la norma de talante legal en cita. A su vez, con la expedición del Decreto 057, objeto del presente análisis, se modificó el citado precepto señalándose en su contenido, entre otros temas, niveles mínimos de aportes solidarios.

Sobre el particular, cabe resaltar que el Consejo de Estado $^{3}$ anuló los transcritos artículos 3 y 7 del Decreto 057 de 2006, así como algunas expresiones del artículo 5 de la misma normativa, y el artículo 2 del Decreto 2825 de 2006, que a su vez había sido modificado el artículo 7 del precitado Decreto 057.

3 Consejo de Estado, Sala de lo Contencioso Administrativo. Sección Cuarta, consejero ponente Hugo Fernando Bastidas Bárcenas, Bogotá, D.C., 25 de marzo de 2010.
La ratio de la decisión judicial en comento se refiere básicamente a la carencia absoluta de competencia y el exceso de la facultad reglamentaria en las que incurrió el Gobierno Nacional en la expedición del citado Decreto 057 de 2006. En efecto, como se indicó en el decurso del presente artículo, la contribución en comento ostenta la calidad de impuesto del orden territorial, siguiendo los lineamientos plasmados en la jurisprudencia constitucional (Sentencia C-086 de 1998); razón elemental por la cual los elementos configurantes de la misma son del resorte exclusivo del legislador que crea el tributo, esto es: determinación de los sujetos activos y pasivos, base gravable, hecho generador y tarifa (art. 338, C.P.) y de la corporación administrativa de representación popular en el plano territorial a la cual se le puede, en estos casos, diferir la competencia para establecer alguno de los citados elementos con base en los parámetros previamente fijados por el legislador, tal como en efecto ocurre tratándose del porcentaje a que hace referencia el artículo 2 de la Ley 632 de 2000.

Corolario de lo anterior es la inviabilidad de pretender por vía reglamentaria establecer alguno de los citados elementos, los cuales en aplicación del principio de vieja data del tributo con representación solamente pueden definirse por el organismo de representación popular (Congreso, Asamblea o Consejo) y no motu proprio por el ejecutivo, tal como en efecto acaeció por conducto de los apartes del decreto analizado y que a la postre fueron declarados nulos por el Consejo de Estado.

Frente al artículo 7 anteriormente referido, la razón invocada por la máxima instancia de lo contencioso administrativo también es elemental. En efecto, el artículo 89.8 de la Ley 142 de 1994, modificado por el artículo 7 de la Ley 632 de 2000, señala con claridad los sujetos obligados a cubrir los déficits causados por subsidios que no alcancen a cubrir los fondos de solidaridad y redistribución de ingresos (entidades del orden nacional, departamental, distrital y municipal). Tampoco se consagra en la 
normativa en comento la categoría de prestadores públicos de los servicios públicos domiciliarios de acueducto, alcantarillado y aseo, circunstancia que además establecería discriminaciones entre entidades territoriales que tengan esa clase de prestadores y las que no, respecto de las cuales no habría entidades obligadas a cubrir el precitado régimen, según la disposición excluida del ordenamiento, generando de esa forma arbitrales injustificados.

El referido fallo tiene efectos de carácter ex nunc, en consonancia con lo señalado sobre el particular en el artículo 38 de la Ley 142 de 1994, lo cual implica que los actos y actuaciones anteriores a la fecha de ejecutoria de la referida sentencia quedan incólumes.

Ahora bien, es pertinente indagar qué pasa con los acuerdos municipales que hayan sido expedidos en los municipios con fundamento en el Decreto 057 de 2006. Frente a ese particular, estimamos que en tono con lo dispuesto en el artículo 66 del Código Contencioso Administrativo, dichos actos administrativos han perdido su fuerza ejecutoria al desaparecer del ordenamiento positivo el fundamento de derecho en que se sustentaban.

En torno a la figura del decaimiento del acto administrativo, la Corte Constitucional ha señalado:

Respecto de la existencia, eficacia, pérdida de fuerza ejecutoria y decaimiento del acto administrativo, recordó la Corporación lo dispuesto en la Sentencia C-069 de1995 en la cual se declaró la exequibilidad del artículo 66 (parcial) del Código Contencioso Administrativo. En lo concerniente a los casos de pérdida de fuerza ejecutoria por sobrevenir una inexequibilidad, expuso que se produce la extinción y fuerza ejecutoria del acto frente a la desaparición de un presupuesto de hecho o de derecho indispensable para la vigencia del acto jurídico, que da lugar a que en virtud de la declaratoria de nulidad del acto $o$ de inexequibilidad del precepto en que este se funda, decretado por providencia judicial, no pueda seguir surtiendo efectos hacia el futuro, en razón precisamente de haber desaparecido el fundamento legal o el objeto del mismo (Corte Constitucional. Sala Sexta de Revisión. Sentencia T-1143 del 10 de noviembre de 2005. Magistrado ponente doctor Marco Gerardo Monroy Cabra).

Lo anterior implica que si bien en virtud del fenómeno del decaimiento del acto administrativo no se afecta la validez intrínseca del acto administrativo, la cual se debe analizar a la luz del ordenamiento vigente en el momento de su expedición, no es posible exigir su cumplimiento coactivo por cuanto ha perdido esa fuerza ejecutoria por carencia de fundamentos de derecho.

El anterior aserto se corrobora con la siguiente cita de un pronunciamiento del Consejo de Estado, en torno a esta materia de discusión:

Pero si bien es cierto, como lo ha sostenido esta Corporación, que la declaración de pérdida de fuerza ejecutoria de un acto administrativo no puede solicitarse al juez de lo contencioso administrativo, pues no existe una acción autónoma que lo permita, no lo es menos que nada impide que con respecto a los actos administrativos respecto de los cuales se ha producido el fenómeno del decaimiento, se produzca un fallo de nulidad, pues en este evento se ataca la configuración de los elementos del acto administrativo al momento de su nacimiento, y su concordancia con el régimen jurídico que debió respetar tanto en su jerarquía normativa, como en el procedimiento para su expedición, mientras que el fenómeno producido por la desaparición del fundamento de derecho de un acto administrativo tiene efectos hacia el futuro sin afectar la validez del acto por todo el tiempo de su existencia jurídica (Consejo de Estado, Sala de lo Contencioso Administrativo, Sección Primera. Consejero ponente Camilo Arciniegas Andrade. Actor: Jorge Enrique Robledo Castillo. Bogotá, D.C., ocho (8) de mayo de dos mil ocho 2008). 
Así las cosas, a nivel de las entidades territoriales habrá que analizar cada caso en particular, en aras de lograr determinar si los actos administrativos expedidos por sus autoridades para lograr el equilibrio entre contribuciones y subsidios se sustentó exclusivamente en el Decreto 057 de 2006, caso en el cual los mismos actualmente no son exigibles, o si por el contrario su fundamento fue directamente la Ley 632 de 2000, caso en el cual los actos administrativos expedidos bajo su egida se mantienen vigentes y exigibles en torno a su cumplimiento, toda vez que la ley sigue vigente dentro del sistema de fuentes que otorgan validez a las disposiciones de inferior jerarquía sustentadas en la misma, conclusión a la que se arriba, siguiendo para el efecto elementales postulados de estirpe kelseniana.

En idéntico sentido se pronunció tanto el Ministerio de Ambiente, Vivienda y Desarrollo Territorial ${ }^{4}$, como la Superintendencia de Servicios Públicos Domiciliarios $^{5}$, instancias gubernamentales que han coincidido en la necesidad de contar con instrumentos normativos a nivel municipal y distrital que dispongan con sujeción a lo dispuesto tanto en la Ley 632 de 2000 como en la metodología prevista en el Decreto 1013 de 2005, mecanismos para lograr el equilibrio financiero entre subsidios y contribuciones, aun en ausencia de los prescripciones del Decreto 057 de 2006, toda vez que subsisten el asidero de talante legal que ampararía esta clase de actos administrativos de forzosa expedición por las autoridades territoriales.

En efecto, para subsanar la situación presentada a raíz del fallo de nulidad precitado, los concejos municipales deben proceder a expedir acuerdos con sustento en la mencionada ley y amparados en la metodología prevista en el de Decreto 1013

4 Ministerio de Ambiente, Vivienda y Desarrollo Territorial, Despacho del Viceministerio de Agua y Saneamiento, Circular 5000-2-90933 del 21 de julio de 2010 .

5 Superintendencia de Servicios Públicos Domiciliarios. Circular Interna No. 20105000000144 del 13 de agosto de 2010. de 2005, y de esa forma propender a lograr el equilibrio financiero entre contribuciones y subsidios como instrumentos que propendan a la sostenibilidad financiera del esquema de subsidios, en consonancia con los referentes constitucionales de solidaridad y redistribución del ingreso.

Especial referencia merece la expedición reciente del Decreto 4715 de 2010, "por el cual se establecen unas reglas que adicionan la metodología para distribución de los recursos provenientes de aportes solidarios en el otorgamiento de los subsidios en los servicios públicos domiciliarios de acueducto y alcantarillado", el cual tiene como ámbito de aplicación los municipios y distritos que cuenten con prestadores de servicios públicos domiciliarios, en materia de acueducto y alcantarillado, que atiendan a su vez más de un municipio o distrito.

Dicha norma se refiere a la figura de la bolsa común que ya estaba contenida en el artículo 4 del citado Decreto 057 de 2006, pero enfocada a los niveles de aporte solidario que establecía prístinamente esa disposición. La actual normativa establece que las entidades territoriales a las cuales se extiende el ámbito de cobertura del citado decreto canalizaran, en una bolsa común de recursos, aquellos destinados al otorgamiento de subsidios, con el fin de distribuir los aportes solidarios entre los suscriptores subsidiables dentro de su ámbito geográfico de cobertura.

A renglón seguido, establece la normativa en comento toda una metodología de carácter técnico para lograr la distribución de los recursos entre los destinatarios de los subsidios con cargo a la mencionada bolsa común, así como disposiciones relativas al esfuerzo local en la materia y alternativas en el evento de afectación del equilibrio financiero entre subsidios y contribuciones que deben aplicar las entidades territoriales.

Dichos preceptos se encontraban contenidos en algunos apartes del Decreto 057 de 2006, que no 
se vieron afectados en su momento por el fallo del Consejo de Estado; pero como se reseñó someramente en forma antecedente, focalizados al modelo que preveía la citada norma, es decir, a los niveles mínimos del factor de aporte solidario, excluido del ordenamiento por las razones ampliamente comentadas en el acápite respectivo.

Por su parte, la nueva norma establece unos desarrollos más específicos de la figura de la bolsa común, señalando una serie de parámetros que no están atados a los niveles mínimos a que hacía referencia la norma declarada nula, sino genéricamente a la facultad que confiere a las entidades territoriales el artículo 2 de la Ley 632 de 2000, en el sentido de ajustar los porcentajes del factor del aporte solidario para asegurar que el monto de las contribuciones sea suficiente para cubrir los subsidios que se apliquen. Sobre ese aspecto, no sobra resaltar que el Decreto 4715 de 2010, en su artículo 6, deroga expresamente el Decreto 057 de 2006 en su integridad, valga precisar en lo referente a las normas que a pesar del pronunciamiento del Consejo de Estado continuaban vigentes hasta ese momento.

Frente al tema que nos ocupa, el nuevo decreto ratifica implícitamente la potestad en cabeza de los concejos municipales y distritales de adoptar los esquemas financieros que propendan por el equilibrio entre subsidios y contribuciones, vía acuerdos municipales o distritales que se sustenten tanto en la Ley 632 de 2000 como en la metodología plasmada en el Decreto 1013 de 2005. El anterior aserto se colige de la estructura de la nueva normativa, la cual parte de un ámbito de cobertura restringido frente al universo de entidades territoriales (personas prestadoras que atiendan a más de un municipio o distrito), y dispone adicionalmente acciones financieras tendientes a lograr el equilibrio financiero entre subsidios y contribuciones que son de competencia de los concejos municipales y distritales, en cuanto a su adopción normativa vía acuerdos, así como a la realización de esfuerzos fiscales locales que coadyuven a lograr arbitrar recursos diferentes a los previstos forzosamente, para robustecer las fuentes de las contribuciones.

\section{CONCLUSIÓN}

De cara a la situación actual del esquema financiero para el otorgamiento de subsidios a nivel de las entidades territoriales, para propender al acceso a la prestación de los servicios públicos domiciliarios a los sectores de menores ingresos, cabe resaltar que si bien se han obtenido significativos avances en materia del proceso de certificación de distritos y municipios, en relación con el manejo de los recursos del sistema general de participaciones, afectados específicamente a la atención de las necesidades básicas insatisfechas en materia de agua potable y saneamiento básico a que alude el artículo 4 de la Ley 1176 de 2007, disposición que modificó la Ley 715 de 2001, todavía subsisten problemas de carácter estructural que amenazan la sostenibilidad financiera en el mediano plazo del esquema de subsidios y su equilibrio frente al monto de las contribuciones y demás ingresos presupuestales necesarios para solventar adecuadamente su concesión.

Dentro de las citadas deficiencias, encontramos a título ilustrativo la falta de pago de las entidades territoriales a favor de las empresas prestadoras, para que estas puedan cubrir adecuadamente los costos necesarios para el otorgamiento de subsidios, obligación que dimana con claridad del numeral 99.8 del artículo 99 de la Ley 142 de 1994, el cual establece que para asegurar la transferencia de los subsidios a las empresas de servicios públicos estas firmarán contratos con los municipios.

En esa misma línea, señala la normativa en cita que cuando los concejos municipales o distritales creen los fondos de solidaridad para subsidios y redistribución de ingresos, y dentro de su dinámica autoricen el pago de subsidios a través de las empresas prestadoras, tomando como fuente de financiamiento para el efecto recursos que sean 
manejados a través de las tesorerías municipales, la transferencia de los respectivos recursos se deberá efectuar en un plazo no superior a treinta (30) días, contados a partir de la misma fecha en que se expida la factura a cargo de la entidad territorial (distrito o municipio). Como instrumento para viabilizar dicha transferencia, las empresas prestadoras suscribirán contratos con el respectivo municipio.

Por su parte, el Decreto 565 de 1996, en su artículo 11 , señaló que para asegurar la mencionada transferencia los recursos destinados a la concesión de subsidios, y que tengan como fuente las tesorerías de las entidades territoriales, deberán ceñirse en su manejo a lo que se estipule en el contrato que para el efecto debe suscribirse entre el municipio, distrito, o departamento y las entidades encargadas de la prestación de los servicios públicos.

Ergo, la suscripción de los contratos tiene por objetivo palmario asegurar la transferencia de recursos para otorgar subsidios, y constituye una obligación exigible a la luz del mencionado marco normativo. Sobre ese particular, la Superintendencia de Servicios Públicos Domiciliarios, por intermedio de la Oficina Asesora de Jurídica, en torno a la obligatoriedad de suscribir los citados contratos como condición sine qua non para la transferencia de los recursos a favor de las empresas prestadoras, ha conceptuado lo siguiente:

\footnotetext{
Ahora bien, respecto de si es o no obligatorio acudir al mecanismo de la suscripción del convenio para el otorgamiento de los subsidios, la Oficina Asesora Jurídica ha sostenido que los municipios y las empresas no pueden excusarse en la inexistencia de convenio para incumplir sus obligaciones constitucionales y legales tendientes al otorgamiento de subsidios, puesto que los subsidios son recursos constitucionalmente protegidos y con destinación específica, razón por la cual si los recursos han sido apropiados por el municipio, y la empresa, a través de una cuenta de cobro o una factura, le solicita el giro de los recursos, es pro-
}

cedente la entrega de los mismos, aunque no se hubiere suscrito el convenio referido (Superintendencia de Servicios Públicos Domiciliarios. Oficina Asesora de Jurídica. Concepto SSPD-OJ-2009-952, del 9 de diciembre de 2009).

Como se observa, la suscripción del citado convenio no es requisito esencial para proceder a efectuar las respectivas transferencias por parte de las entidades territoriales a favor de las empresas prestadoras, para financiar el otorgamiento de subsidios a los usuarios de menor ingreso. No obstante lo cual muchas entidades de ese nivel administrativo continúan renuentes a efectuar las citadas transferencias a favor de los prestadores circunstancia que milita en contra de la estabilidad del sistema de financiación de subsidios en el plano territorial y que en ocasiones ha implicado el inicio de procesos judiciales para pretender por vía coactiva el logro del pago de los recursos respectivos. Este aspecto entorpece en grado sumo la gestión pública territorial y causa traumatismos en el normal desenvolvimiento de la institucionalidad en ese nivel.

Por otro lado, después del fallo proferido por el Consejo de Estado al cual hemos hecho referencia en el decurso del presente artículo, el artículo 6 del Decreto 057 de 2006, concordante con el Decreto 1013 de 2005, continuaba vigente hasta la expedición del Decreto 4715 de 2010; en el citado precepto se establecía que en el evento de no lograrse el equilibrio entre subsidios y contribuciones, podrían seguirse los procedimientos contemplados en la misma disposición. El citado artículo, frente a ese tema de estudio, disponía lo siguiente:

\footnotetext{
Artículo 6. Cuando no se haya logrado el equilibrio entre subsidios y contribuciones, podrán seguirse, entre otros, cualquiera de los siguientes procedimientos o su combinación, a fin de procurar el mencionado equilibrio:
}

El alcalde municipal o distrital podrá solicitar a la empresa prestadora que se apliquen los porcentajes de subsidios 
que este defina, para lo cual deberá comprometerse a cubrir los faltantes generados.

Las personas prestadoras podrán aplicar, como política comercial, los niveles de subsidios que, dentro de los topes establecidos en la norma vigente, consideren apropiados, para lo cual podrán establecer transiciones sin poner en riesgo su suficiencia financiera.

3. El municipio o distrito de manera conjunta con las personas prestadoras, podrá acordar alternativas para ajustar los subsidios en el tiempo, de acuerdo con las condiciones de disponibilidad de recursos.

El artículo 5 de la normativa vigente reproduce los transcritos literales 1 y 3, (artículo 5, Decreto 4715 de 2010), eliminando el numeral 2 original relativo a la política comercial, el cual hacía referencia a los topes establecidos que hoy en día no existen por virtud del fallo de nulidad proferido por el Consejo de Estado y por cuanto es del resorte de cada entidad territorial su establecimiento al amparo del artículo 2 de la Ley 632 de 2000, tal como se ha resaltado a lo largo del presente artículo.

En efecto, el mecanismo de la bolsa inicialmente previsto en el Decreto 057 de 2006, ante la declaratoria de nulidad de los porcentajes señalados en esa disposición, devenía inexorablemente en inane y era menester en consecuencia establecer un modelo diferente, tal como lo hizo el actual Decreto 4715 de 2010, el cual no se enfoca a porcentajes, sino a fuentes de financiamiento y metodología técnica de redistribución frente a los beneficiarios, reconociendo el margen de maniobra que a nivel normativo tienen las entidades territoriales para definir los porcentajes necesarios para propender por el equilibrio entre contribuciones y subsidios (artículos 4 y 5 del Decreto 4715 de 2010).

De lo anterior se colige que cuando no se haya logrado el equilibrio entre subsidios y contribuciones, el proceder de la entidad territorial debe supeditarse a los supuestos enunciados. Nótese cómo la obligación de transferir recursos por parte de los distritos o los municipios a favor de la empresa prestadora surge cuando la cuantía de los subsidios proyectados es mayor al valor recaudado por concepto de contribuciones, en aras de subsanar el respectivo déficit.

Para finalizar, es menester señalar que las entidades territoriales que aún no han creado los fondos de solidaridad y redistribución de ingresos, y no hayan apropiado las partidas presupuestales necesarias para suplir el déficit entre subsidios y contribuciones, se verían avocados a una situación en la cual la alternativa sería ajustar la tarifa disminuyendo el otorgamiento de subsidios en perjuicio de la población más vulnerable; circunstancia que obligaría con urgencia a expedir los actos necesarios para garantizar el equilibrio financiero entre ambas variables con sustento en lo normado en la Ley 632 de 2000 y en el Decreto 1013 de 2005 , fijando los porcentajes del aporte solidario a través de los organismos de representación popular.

La viabilidad del esquema financiero para el otorgamiento de subsidios en el mediano y largo plazo depende, entre otras variables, de la disciplina y el esfuerzo fiscal en el plano territorial, así como del establecimiento de políticas sectoriales que proyecten robustecer la generación de recursos encauzados a materializar teleológicamente las finalidades de solidaridad y redistribución, concebidos como insumos que permitan la estructuración de políticas públicas que requieren necesariamente de un subyacente presupuestal, el cual sirva como garante para responder con eficacia a los retos que demanda el materializar los derechos fundamentales en el seno de un auténtico Estado social de derecho.

\section{REFERENCIAS}

Bedoya Giraldo, H. (1997). Fondos de solidaridad y redistribución de ingresos. Letras Jurídicas, EEPP de Medellín, 2, 2. 
Castro Nieto, H. (2010, junio). Comentarios al régimen de subsidios y contribuciones en el sector de agua potable y saneamiento básico: Problemas actuales. Revista ANDESCO, 20.

Comisión de Regulación de Agua Potable y Saneamiento Básico, CRA. Concepto CRA-OJ 4216. Noviembre 30 de 2004.

Consejo de Estado, Sala de lo Contencioso Administrativo, Sección Primera. Consejero ponente Camilo Arciniegas Andrade. Actor: Jorge Enrique Robledo Castillo. Bogotá, D.C., ocho (8) de mayo de dos mil ocho (2008). Radicación número: 1100103-24-000-2003-00487-01.

Consejo de Estado, Sala de lo Contencioso Administrativo, Sección Tercera. Consejero Ponente: doctor Ramiro Saavedra Becerra. Bogotá, D.C., treinta y uno (31) de julio de dos mil tres (2003). Radicación No. ACU- 25000-23-24-000-2002-02855-01.

Consejo de Estado, Sala de lo Contencioso Administrativo. Sección Cuarta. Consejero Ponente: Hugo Fernando Bastidas Bárcenas. Bogotá, D.C., veinticinco (25) de marzo dos mil diez (2010). Radicado: 11001-03-27-000-2006-00025-00-16078.
Corte Constitucional. Sala Plena. Sentencia C-086 de 1998. Magistrado Ponente: doctor Jorge Arango Mejía, marzo 18 de 1998. Expediente D-1771.

Corte Constitucional. Sala Sexta de Revisión. Sentencia T- 1143 del 10 de noviembre de 2005. Magistrado Ponente: doctor Marco Gerardo Monroy Cabra.

Corte Constitucional. Sala Sexta de Revisión. Sentencia T-381 del 28 de mayo de 2009. Magistrado Ponente: doctor Jorge Ignacio Pretelt.

Díaz Arenas, P.A. (1994). Estado y tercer mundo. Bogotá: Editorial Temis.

Ministerio de Ambiente, Vivienda y Desarrollo Territorial, Despacho del Viceministerio de Agua y Saneamiento. Circular 5000-2-90933 del 21 de julio de 2010.

Superintendencia de Servicios Públicos Domiciliarios. Circular Interna No. 20105000000144 del 13 de agosto de 2010.

Superintendencia de Servicios Públicos Domiciliarios. Oficina Asesora de Jurídica. Concepto SSPDOJ-2009-952, del 9 de diciembre de 2009. 